\title{
A origem do universo como tema para discutir a Natureza da Ciência no Ensino Médio ${ }^{+*}$
}

Gustavo Antonio Montenegro Guttmann ${ }^{1}$

Cefet-RJ - Uned

Nova Friburgo - RJ

Marco Braga ${ }^{2}$

Cefet-RJ

Rio de Janeiro - RJ

\section{Resumo}

Nesse artigo será apresentada uma proposta de introdução de questões relativas à Natureza da Ciência a partir da confrontação de duas teorias distintas sobre a origem do universo. Esse trabalho foi desenvolvido junto a turmas de Ensino Médio de uma escola do Rio de Janeiro. As teorias são divergentes, sendo uma defensora de um universo com uma origem definida, o Big Bang, e a outra de um Universo Eterno. Ao final do trabalho foi possível aferir que os alunos passaram a ter uma visão mais complexa sobre Ciência.

Palavras-chave: História da Ciência; Natureza da Ciência; Filosofia da Ciência.

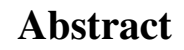

This paper presents an educational activity in which the Nature of Science is discussed from a confrontation between two distinct theories about the origin of the universe. These activities were developed in a high school in Rio de Janeiro. These theories are divergent; one defends that the universe has a defined origin, the Big Bang, and the other an

\footnotetext{
${ }^{+}$The origin of the universe as a topic to discuss the Nature of Science in High School

* Recebido: setembro de 2014. Aceito: abril de 2015.

${ }^{1}$ E-mail: gusgutt@gmail.com

2 E-mail: bragatek@cefet-rj.br
} 
Eternal Universe. At the end of the activities it was possible to verify that the students developed a more complex vision of Science.

Keywords: History of Science; Nature of Science; Philosophy of Science.

\section{Introdução}

As disciplinas do Ensino Médio hoje deveriam ter por base a formação de competências dos alunos e não somente a acumulação de conhecimentos e conteúdos de forma estanque. Uma das competências que se deseja desenvolver é a compreensão dos processos de construção do conhecimento científico, ou como ficou conhecida, a Natureza da Ciência $(\mathrm{NdC})$. Esse viés situa-se normalmente fora do dia a dia das salas de aula, sendo que sua introdução acaba ocorrendo no interior das disciplinas científicas a partir de empreitadas individuais de professores interessados pelo tema.

A Associação Americana para o Progresso da Ciência ${ }^{3}$ (AAAS,) lançou, em 1985, um projeto de revisão dos currículos escolares desde o sexto ano do Ensino Fundamental até o terceiro ano do Ensino Médio. Nesse projeto, chamado de 2061, pretende-se que todo cidadão americano seja alfabetizado cientificamente até o ano de 2061, o qual antecede a próxima passagem do cometa 1P/Halley. Para tanto, foi proposta uma reforma do currículo em que, além de deixa-lo mais contextualizado, visa introduzir questões referentes à Natureza da Ciência, isto é, questões que tratam dos processos de construção do conhecimento científico. Com isso, conteúdos de História e Filosofia das Ciências (HFC), que já vinham ganhando importância no Ensino Médio desde o Harvard Project, passaram a exercer um importante papel na construção do novo currículo de toda a formação científica americana (MATTHEWS, 1995).

O documento do projeto, denominado "Science for all Americans" contém dez capítulos. O primeiro capítulo é dedicado à discussão sobre "Natureza da Ciência". Essa discussão contempla diversos itens, como "a objetividade e mutabilidade da ciência", "provas científicas e suas relações com a justificativa da teoria", "explicação e predição", "ética", "política e organização social da ciência". Um aspecto importante é que todos esses assuntos não devem substituir os conteúdos das disciplinas relacionadas à ciência, mas que o aluno ao final desse segmento tenha um conhecimento básico acerca deles.

Na introdução do décimo capítulo são apresentadas duas justificativas para o ensino de História da Ciência: o primeiro é o fato de que as afirmações sobre o funcionamento dos

\footnotetext{
${ }^{3}$ AAAS - American Association for the Advancemente of Science. Disponível em: <http://www.aaas.org/>. Acesso em: 20 mar. 2015.

${ }^{4}$ Science for all Americans. Disponível em: <http://www.project2061.org/publications/sfaa/online/sfaatoc.htm>. Acesso em: 20 mar. 2015.
} 
empreendimentos científicos não têm sentido se não forem fornecidos exemplos concretos; o segundo é que alguns fatos históricos da pesquisa científica são bastante significativos para a nossa herança cultural.

Aprofundando as ideias apresentadas no capítulo dez desse documento, diversos autores (MATTHEWS, 1995; GUERRA et al., 2002; PEDUZZI; KÖHNLEIN, 2005) vem apresentando argumentos para defender propostas de que mais do que a exposição de fatos históricos sobre a construção da Ciência, um ensino contextualizado deve apresentar controvérsias científicas. Com essa visão o aluno pode perceber que a construção da ciência não se dá de uma forma linear nem por meio de descobertas de teorias e leis existentes na Natureza. Além disso, eles poderiam perceber os diferentes fatores que fizeram com que a ciência assumisse o seu papel e formato atual.

A Educação em Ciências tem como um dos seus objetivos fazer com que o aluno venha a compreender o olhar da ciência para o mundo, ou seja, interpretar o mundo desde o ponto de vista científico, manejar alguns conceitos, leis e teorias, abordar problemas raciocinando cientificamente, identificar aspectos históricos, epistemológicos, sociais e culturais das ciências (PINO et al., 2003).

Assim a utilização de projetos que envolvam questões histórico-filosóficas faz com que o currículo se enriqueça e permite que os alunos percebam de forma concreta o processo de construção do conhecimento científico, superando até a ideia de que existe um "método científico" que conduza à "verdade". Essa proposta pode ajudar a quebrar a imagem que a ciência e até mesmo o cientista tem no senso comum. Rubem Alves (2012) apresenta a importância de se quebrar o mito de que o cientista é uma pessoa que pensa melhor que as outras. Ele apresenta como uma consequência de não se quebrar essa imagem a produção de pessoas que se eximem de pensar já que outro o faz por ela.

Esse tipo de trabalho, utilizando História e Filosofia da Ciência bem como noções sobre Natureza da Ciência se alinham com autores como Matthews (1995), McComas (2008) e Höttecke e Riess (2009). Dentro de nosso sistema educacional, um dos documentos mais importantes para nossa prática educativa, os PCNs, não promovem a inclusão desse aspecto do ensino de Ciências. Utilizando como referencial teórico epistemólogos contemporâneos como Kuhn, Lakatos, Bachelard, Toulmin e Popper, pesquisadores como Pino, Ostermann e Moreira (2003) mostram como os PCNs tem uma tendência de levar um leitor desavisado a uma interpretação de Ciência como empirista-indutivista. Além disso, mostram também que o texto leva a uma interpretação que Ciência se faz pelo acumulo de conhecimento ao longo do tempo.

McComas (2008) busca exemplos históricos que evidenciem aspectos de Natureza da Ciência e ressalta que uma real reforma do currículo de Ciências precisa incluir tal característica. Ele apresenta recomendações da U.S. National Science Education Standards, onde se inclui como elemento essencial aspectos da Natureza da Ciência no currículo de Ciências. Höttecke e Riess (2009) apresentam cinco argumentos para implementação de um currículo 
histórico-filosófico para a discussão da Natureza da Ciência: promover um melhor entendimento de conceitos e métodos científicos, entender como a ciência está imersa na cultura e que esses métodos e conteúdos científicos são produções humanas, desenvolver um adequado entendimento da Natureza da Ciência. Espera-se que com essa abordagem poder-se-á neutralizar o cientificismo, o dogmatismo e descrições simplificadas dos processos científicos. Assim se possibilita uma maior compreensão dos fundamentos filosóficos da ciência tornando a visão do aluno mais adequada para o exercício de sua cidadania.

Dentro da convicção do valor da inserção de HFC e de Natureza da Ciência, Höttecke e Riess (2009) apresentaram um projeto europeu para superar as dificuldades de implantação de práticas que utilizem essa abordagem para o ensino. Esse é um projeto de parceria entre diversos países. Entre os principais objetivos desse projeto estão o aumento da inclusão de HFC no ensino de Ciências para beneficiar a alfabetização científica, melhoraria das estratégias para a implementação e desenvolvimento de materiais e metodologias de ensino-aprendizagem na prática educativa. Ainda no escopo do projeto, pode-se encontrar a criação de uma rede de cooperação para estabelecer uma infraestrutura permanente de interessados em alfabetização científica e afins.

Esses trabalhos mostram a importância de se desenvolver estratégias e materiais relacionados à HFC e Natureza da Ciência para um melhor desenvolvimento e aceitação dessa abordagem em sala de aula. Boa parte dos professores da área de Ciências já pode ter sido questionada pelo formato que ministra a matéria e pelos conteúdos selecionados como essenciais dentro dela. Matthews (1995) coloca que a HFC pode não resolver completamente esse problema, mas pode humanizar as Ciências aproximando-a de grupos com diferentes interesses. Pode ainda tornar as aulas mais reflexivas e consequentemente menos matematizadas, dando maior significados para as disciplinas dessa área.

Apesar de não se discutir abertamente a inclusão de temas de HFC nos PCNs, Guerra, Braga e Reis (2009) explicitam a necessidade de se introduzir questões históricofilosóficos de Física contemporânea no Ensino Médio, promovendo uma mudança na prática da maioria dos professores desse segmento. Muitas vezes os docentes ficam presos aos programas de vestibulares que contemplam em sua maioria a Física do século XIX. Uma pesquisa realizada corrobora com tal análise, pois de dez professores entrevistados, sete nunca haviam trabalhado com Física Moderna e Contemporânea no Ensino Médio (OLIVEIRA et al 2007 apud Guerra, Braga e Reis, 2009). Apesar das recomendações dos documentos oficiais, as mudanças em relação aos conteúdos abordados em sala foram pequenas.

O Programa Ensino Médio Inovador, ProEMI, instituído pela Portaria $n^{0} 971$, de 09/10/2009, foi criado para promover o debate sobre o Ensino Médio junto aos Sistemas de Ensino Estaduais e Distritais. Esse programa tem como um de seus objetivos a reformulação do currículo adotado para o Ensino Médio, denominado Projeto de Redesenho Curricular (PRC). Pretende-se que o currículo torne-se mais adequado as diferentes realidades do país. Esse documento oferece orientação para trabalhos que propõem mudanças curriculares em 
consonância com as Diretrizes Curriculares Nacionais para o Ensino Médio (Resolução CNE/CBE 02/2012).

No Documento Base do ProEMI é apresentado um referencial de tratamento curricular indicando as condições básicas para implantação do PRC. Duas orientações abrem um viés onde $\mathrm{HFC}$ e NdC se tornam uma proposta muito adequada.

A primeira diz:

Foco em ações elaboradas a partir das áreas de conhecimento conforme proposto nas Diretrizes Curriculares Nacionais para o Ensino Médio e que são orientadoras das avaliações do ENEM.

Para que as Ciências da Natureza se transformem efetivamente em uma área do conhecimento no currículo se faz necessário um diálogo amplo entra as disciplinas dessa área. Assim, faz-se necessário a busca por elementos que possam funcionar como um "ligante" entre a Física, a Química e a Biologia. Uma proposta didática baseada em HFC e Natureza da Ciência pode se apresentar como uma solução real e exequível para essa proposta.

A segunda orientação que se mostra interessante a implantação de HFC e NdC no currículo apresenta o seguinte texto:

Oferta de ações que poderão estar estruturadas em práticas pedagógicas multi ou interdisciplinares, articulando conteúdos de diferentes componentes curriculares de uma ou mais áreas do conhecimento.

Esta segunda orientação complementa a primeira. Ela reforça a necessidade natural de se trabalhar de forma interdisciplinar dentro uma área do conhecimento. Porém ela abre uma busca por diálogo entre as diferentes áreas do conhecimento. Mais uma vez os trabalhos desenvolvidos em sala de aula onde se discute HFC e Natureza da Ciência se apresentam alinhados a ideia proposta pelo documento.

\section{O problema das origens}

A partir de debates do grupo de pesquisa no Centro Federal de Educação Tecnológica, Cefet/RJ, sobre as relações entre Epistemologia e o Ensino de Ciências, surgiram questionamentos sobre algumas questões-chave que permanecem ao longo da história da humanidade. Uma delas é a da existência ou não de uma origem do universo e as diferentes respostas que foram apresentadas ao longo dos tempos. Diversos filósofos debateram essa questão desde os gregos. Nos últimos séculos tal questão ficou a cargo dos cientistas, sendo que os físicos vêm trabalhando sobre a origem do universo e os biólogos sobre a origem da vida. Embora hoje tal questão não seja motivo de grandes polêmicas na Física, devido à hegemonia da teoria do Big-Bang, existem vozes discordantes que defendem o modelo de um Universo Eterno (NOVELLO, 2010). 
A divulgação que a mídia vem dando ao modelo do Big Bang e de fatos a ele relacionados faz com que a maior parte dos alunos, e da sociedade em geral, não tome conhecimento de outra possibilidade de interpretação para origem do universo. Recentemente a própria divulgação do começo da operação do acelerador de partículas LHC (Large Hadron Collider) no CERN (European Organization for Nuclear Research) em Genebra levantou o tema na mídia através da possibilidade de reprodução das condições iniciais de ocorrência do Big Bang.

Lima e Takahashi (2008) verificaram através de uma pesquisa com alunos de cursos de áreas exatas em semestres iniciais que estes se interessam bastante pelo assunto "origem do universo". Porém a visão sobre a origem do universo se mostraram bastante distorcidos, pois os alunos não conheciam outros modelos que, no passado, tiveram o mesmo peso do hegemônico atual. Além disso, tais alunos desconhecem que ainda hoje existem vozes discordantes trabalhando com modelos alternativos.

Esse fato mostra que embora esses estudantes tenham acesso às informações sobre teorias contemporâneas, os mesmos desconhecem por completo as discussões que foram ou têm sido feitas acerca desses experimentos. Sob a desculpa de se apresentar os conteúdos didaticamente, os currículos impõem a velha proposta de Auguste Comte de que o melhor caminho para se ensinar algo é aquele que concebe o conhecimento como tendo sido elaborado por uma única mente (Braga, 2000). Controvérsias não tem assento nas escolas. Com isso, as visões sobre a Natureza da Ciência acabam sendo altamente deturpadas pelo simples "esquecimento", tanto nas escolas como nos meios de comunicação, da existência de controvérsias no passado ou de modelos alternativos aos defendidos ainda hoje pelo "mainstream" científico.

\section{O Big Bang}

O Big Bang é o modelo para origem do universo considerado hegemônico na atualidade. Por esse motivo foi escolhido como tema motivador para se discutir em sala de aula conflitos naturais da construção da ciência. A sua hegemonia pode ser colocada em discussão no momento em que se apresenta um modelo concorrente. Mais do que tornar os alunos conhecedores de assuntos relacionados à cosmologia, o objetivo do trabalho é poder discutir como modelos são construídos, como eles dialogam e como um modelo se torna hegemônico em relação ao outro.

O Big Bang tem sua origem quando Einstein desenvolve suas equações da relatividade. Devido a sua concepção sobre como se formou o universo, inicialmente ele propôs que houvesse uma constante em suas equações que faria um papel de "anti-gravidade". Essa constante foi denominada de "cosmológica" e tinha o papel de possibilitar a interpretação de um universo eterno, como ele acreditava (NOVELLO, 2006).

Porém um matemático russo Alexander Friedmann resolve as equações da relatividade sem a constante cosmológica. $\mathrm{O}$ resultado apresentou um universo em expansão em que 
seu tamanho no passado fora menor que hoje. Isso indicava que em dado momento o universo teria sido muito pequeno (NOVELLO, 2006). Posteriormente, essa interpretação seria retomada por Georges-Henri Édouard Lemaître, um clérigo belga, que ainda propôs que deveria ter havido um átomo primordial que deu origem a tudo (SINGH, 2004).

Por duas vezes Einstein negou os resultados das equações de Friedmann apontando para um universo finito. Na primeira, Einstein recusou um trabalho de Friedmann quando este foi submetido a uma revista científica. A segunda ocorreu no famoso congresso de Sovay, quando Lemaitre apresentou seus resultados para Einstein, sendo, entretanto, refutado por ele. No futuro Einstein afirmou se arrepender destes fatos, após ele próprio mudou sua concepção sobre o universo, admitindo a origem na grande explosão (SINGH, 2004).

A primeira evidencia utilizada a favor da interpretação do Big Bang veio por Edwin Hubble (NEVES, 2000). Em suas observações astronômicas, ele percebeu um desvio para o vermelho do espectro de uma galáxia que era observada. Isso foi interpretado como um afastamento dessa galáxia. Assim ele conseguiu verificar que o universo hoje é maior do que foi ontem.

Na década de 60, nova evidencia foi observada pelos radioastrônomos Arno Penzias e Robert Wilson (SINGH, 2004). Eles registraram uma radiação de micro-ondas de 3,5 K de temperatura. A princípio acharam que era uma interferência indesejada nas suas medidas. Quando começaram a pesquisar a causa de tal ruído eletrônico, descobriram que a radiação vinha de todas as direções.

Começava, então, a ser construída a hegemonia da teoria do Big Bang. Por conta dessa descoberta. Penzias e Wilson foram agraciados com o premio Nobel de Física de 1978.

\section{O Universo Eterno}

Para descrever esse modelo foi usado como referencial teórico o trabalho do cosmólogo brasileiro Mario Novello. Ele defende que o universo é eterno não tendo um ponto de partida.

Segundo Novello:

Não é raro que uma proposta científica relevante seja precipitadamente posta de lado, ou mesmo rejeitada como ineficiente, graças ao mau uso de uma de suas características ou a aplicação equivocada de uma formulação teórica particular a ela associada (NOVELLO, 2010, p. 68).

O cosmólogo brasileiro defende que a concepção de um universo eterno foi precocemente abandonada devido à descrição proposta pela teoria do Steady State (BONDI; GOLD, 1948). Essa teoria apresentava uma configuração do universo como eterno e estático. Com observações que apontavam para um universo mais quente no passado do que no presente, acabou por derrubar a hipótese do estático. Porém Novello aponta que essa observação derruba somente a hipótese do estático e não do eterno. Assim, para Novello, ainda hoje, 
quando se critica o Big Bang, os cosmólogos entendem que se esteja retomando o modelo do Steady State.

Em 1998, observações de supernovas levaram a formulação de uma proposta de que o universo estaria em expansão acelerada. Essa proposta foi rapidamente aceita pelos cosmólogos e pode ser colocada como um ponto de reflexão acerca do modelo com singularidade inicial como o Big Bang. A expansão do universo foi usada como comprovação para o Big Bang, porém essa expansão deveria ser retardada devido à atração entre massa. A grande explosão provocou a expansão, mas a atração de natureza gravitacional faria com que essa expansão fosse desacelerada.

Esse fato abriu então espaço para defesa de um universo eterno em que esse modelo não apresenta uma configuração estática, mas sim dinâmica. Diversos modelos defendem esse tipo de "leitura" do universo. Para Novello, em especial, o Modelo Magnético se mostra mais adequado. Porém, não é objeto dessa pesquisa a descrição específica dos modelos, mas sim a controvérsia por trás deles. Essa controvérsia se caracteriza pelas questões de finito x infinito e como uma teoria pode sobrepujar outra.

\section{A pesquisa}

Esse trabalho foi desenvolvido como uma pesquisa para levantar, junto a alunos de Ensino Médio, concepções sobre a possibilidade ou não do universo ter uma origem temporal. Além disso, deseja-se avaliar o impacto de atividades que envolvam Natureza da Ciência nesse grupo de alunos. O grupo foi composto por cento e dezessete alunos, de dezesseis anos, oriundos de classe média e que tem acesso aos diversos meios de informação como internet, livros e revistas de divulgação científica. A instituição de ensino que abrigou o trabalho se apresenta aos pais como tendo como característica principal a formação crítica de seus alunos.

A série escolhida foi o segundo ano do Ensino Médio. O grupo havia acabado de estudar Gravitação de forma convencional, utilizando a sequência do livro didático adotado pela escola. Essa escolha se deu com o objetivo de contrastar as discussões previamente realizadas, de forma bem matematizada, com uma discussão mais crítica e contemporânea. Durante as aulas de Gravitação os alunos estudaram as Leis de Kepler, Gravitação Universal de Newton e aplicações dessas Leis.

Um questionário introdutório, aberto, foi aplicado visando captar as concepções dos alunos sobre o tema. Esse questionário foi complementado com observações e alguns relatos feitos durante o desenvolvimento junto às turmas. Posteriormente, dividiu-se cada turma em dois grupos, sendo que cada grupo deveria defender um modelo cosmológico: um o Big Bang e o outro o Universo Eterno segundo Novello. Os grupos puderam buscar materiais na internet e um texto de apoio sobre os dois modelos foi entregue a eles. Após uma semana, foi promovido um grande debate e cada grupo defendeu sua posição. Ao final, fez-se uma mesa redonda para discussão das duas perspectivas e foi aplicado um pós-teste na semana seguinte ao trabalho para se avaliar como havia ficado a discussão para os alunos. 


\section{Questionário para pré-teste}

1- Qual a sua orientação religiosa:

( ) Católico ( ) Judeu ( ) Espírita ( ) Protestante ( ) Outra religião

2- Você já pensou sobre a origem do universo?

( ) $\operatorname{Sim}$ ( ) Não

3- Caso a resposta anterior tenha sido positiva, qual a explicação que você aceita?

4- Você conhece a palavra Cosmologia? O que ela significa?

5- Um mesmo fenômeno pode ter duas explicações científicas diferentes e corretas?

6- Acaso uma venha a prevalecer sobre a outra, que fatores podem levar a essa maior aceitação?

$\mathrm{O}$ questionário foi respondido pelo universo de alunos descritos anteriormente. $\mathrm{O}$ formulário de respostas não era identificado e a sua entrega não foi supervisionada pelo professor nem por qualquer outro representante da instituição. Essa questão foi colocada claramente no início dos trabalhos em cada turma. Após a aplicação os questionários foram identificados como A, B ou C, devido a três turmas terem participado, e numerados aleatoriamente.

A primeira pergunta serviu para situar a opção religiosa dos alunos. Apesar de o colégio ser gerido por uma ordem religiosa católica, sua tradição provém de uma liberdade de escolha de religião, tanto por parte do corpo docente como discente. Ainda assim, o fato de ser um colégio confessional, tende a indicar a opção religiosa dos pais e, por consequência, dos alunos.

A tabela abaixo apresenta a distribuição de respostas entre as opções apresentadas no questionário.

A opção "ateu" não aparecia no questionário. Porém alguns alunos escreveram essa opção sendo um resultado expressivo conforme tabela I.

Tabela I - Distribuição das respostas da primeira questão.

\begin{tabular}{|l|c|}
\hline Católicos & $45 \%$ \\
\hline Judeu & $1 \%$ \\
\hline Espirita & $9 \%$ \\
\hline Protestante & $2 \%$ \\
\hline Outra & $23 \%$ \\
\hline Ateu & $21 \%$ \\
\hline
\end{tabular}


A questão religiosa foi abordada, pois questões de cunho filosófico podem ser orientadas por opções religiosas. A origem do universo pode ser relacionada à questão do Divino, contribuindo para convicção do aluno.

A segunda pergunta, apesar de ser fechada, teve a maior parte das respostas indicando que os alunos pensam sobre a origem do universo. Apenas oito alunos responderam que nunca haviam pensado sobre a origem do universo.

Como esta pergunta teve a maioria das respostas indicando que o grupo já havia pensado sobre a temática, a terceira pergunta teve um alto índice de respostas. Como era de se esperar, devido à sua grande divulgação, a teoria do Big Bang apareceu na maioria das respostas. Porém, apenas $10 \%$ tentaram dar uma explicação sobre essa teoria. Isso de certa forma é surpreendente, pois esses alunos possuem fácil acesso à informação, e esse modelo cosmológico é largamente difundido na mídia não especializada. Uma hipótese que se levanta é de que o fato da informação estar largamente difundida não quer dizer que quem tem acesso a ela a incorpore.

Entre as respostas encontra-se uma inquietação sobre as causas do Big Bang e o que havia antes dele. Esse tipo de questionamento levanta um outro, que as matérias relacionadas às Ciências podem desenvolver junto aos seus alunos. Abrir espaços para discutir essas questões de cunho científico-filosófico traz a oportunidade de fazer com que alunos com diferentes áreas de interesse possam contribuir e participar. Esse fato corrobora a discussão inicial desse artigo sobre a inserção de História e Filosofia das Ciências, não como um apêndice dos conteúdos, mas sim como um fator problematizador e motivador à participação dos alunos. Além disso, essas respostas podem indicar como um assunto contemporâneo pode levar a uma discussão onde a participação do aluno é mais ativa.

Outro aspecto que chama a atenção é que apenas $6 \%$ dos alunos escreveram aceitar que o universo foi criado por Deus. Apesar de o colégio ser católico, e a maioria dos alunos seguirem essa Igreja, a proposta pedagógica da instituição se apresenta como libertadora e seu corpo discente questionador. Assim, essa incidência de resposta, justificando a origem baseada em Deus, pode ser compreendida.

Entre os alunos, $4 \%$ deles responderam que o universo sempre existiu e que eles não acreditavam em um momento inicial, alegando que o mesmo não poderia ter surgido partir do nada.

Provavelmente, esse grupo de alunos, que tem em seu currículo filosofia, não teve contato com as ideias de Parmênides e muito menos com alguma hipótese moderna que defenda o Universo Eterno. Entretanto, a ideia por eles defendida, de infinitude, encontra respaldo em diversos grupos existentes hoje que não aceitam a teoria do Big Bang. Ao longo do trabalho que foi desenvolvido se apresentou a hipótese do Universo Eterno, buscando contrastar com a ideia de uma grande explosão criadora e mostrando que duas hipóteses concorrentes podem coexistir, dialogar e debater, buscando mais evidências a seu favor. 
Na pergunta de número quatro, 66\% dos alunos responderam que já ouviram falar sobre Cosmologia. Porém, no momento de explicar o seu significado, os alunos fizeram uma análise morfológica da palavra, concluindo que Cosmologia seria o estudo do cosmo. Essa explicação mostra que, na realidade, eles não conhecem os temas tratados pela Cosmologia moderna.

As questões cinco e seis são inter-relacionadas. Um fato interessante foi as justificativas apresentadas. Independente da resposta da questão cinco, onde o aluno acredita que poder existir uma ou duas teorias para explicar o mesmo fenômeno, as justificativas para questão seis tiveram o mesmo teor. Assim, a seguir, são apresentados os resultados dessas questões analisados em conjunto.

Um fator é que para $35 \%$ dos alunos as comprovações científicas, experimentais ou matemáticas são os fatores mais determinantes nessa seleção de teorias vitoriosas. Outro traço interessante que pode ser percebido é que $9 \%$ responderam que a facilidade de entendimento da teoria é um fator importante para levar uma teoria a ser mais aceita. Esse grupo mostra que, de certa forma, a simplicidade de uma teoria faz com que ela tenha uma maior aceitação pelo público geral. A simplicidade aqui fica entendida como sendo a teoria baseada na experimentação e na explicação matemática do fenômeno observado. Os positivistas defendiam que teorias que descrevam a natureza devem ser simples e sem referências metafísicas, caso contrário deveria conter algum erro. Um aluno que chega ao Ensino Médio, após passar pelo Fundamental, onde a maioria dos livros de Ciências possui perfil positivista (Braga, Guerra e Reis, 2008) pode os ter levado a achar que sempre prevalecem teorias simples e didática e cronologicamente organizadas.

Apesar de não ter sido a maioria das respostas, $32 \%$ dos alunos disseram que só pode existir uma teoria que explique um fenômeno.

\section{O desenvolvimento do trabalho}

Após o levantamento feito através do pré-teste, desenvolveu-se um trabalho junto às turmas, a fim de se provocar uma mudança nas concepções apresentadas pelos alunos. Não se espera que o trabalho resolva questões tão complexas com Finitude $x$ Infinitude ou a concepção individual de cada aluno sobre a origem do universo. Porém, a discussão do tema levanta um questionamento entre os alunos fazendo com que se desenvolva o senso crítico deles em torno do assunto.

Com o objetivo de se discutir sobre o tema e, principalmente, despertar no grupo uma postura reflexiva sobre a construção da Ciência, foi aplicado um texto de apoio onde se descreve o surgimento da cosmologia bem como a consolidação de dois modelos cosmológicos mais atuais: o primeiro, e hegemônico, chamado de Big Bang; o segundo, defendido pelo cosmólogo brasileiro Mario Novello, que se opõe ao Big Bang, defende que o universo é dinâmico e eterno, chamado no trabalho de Universo Eterno. 
Com essa controvérsia, esperava-se que os alunos percebessem a coexistência de teorias concorrentes e se explicita a discussão "Finito x Infinito". Seguindo a teoria proposta por Stephen Toulmin (1956), espera-se que os alunos passem a admitir a existência de diferentes teorias e que estas lutem até que uma prevaleça sobre a outra.

Braga, Guerra e Reis (2002) utilizaram um julgamento simulado para que os alunos desenvolvessem um momento de leitura e reflexão sobre história e filosofia da Ciência. Assim, a motivação do julgamento fez com os alunos buscassem informações sobre o tema julgado. Com a mudança de papel para o aluno, onde ele passa a ser proativo na busca de informações, a atividade teve uma boa avaliação por parte dos discentes.

Pressupondo a mesma ideia, ao invés de mandar os alunos somente lerem um texto sobre teorias cosmológicas e avaliá-los após a leitura, foi feita uma proposta diferente. Cada turma se dividiu em seis grupos. Três grupos deveriam defender o modelo do Big Bang e os outros três grupos o modelo do Universo Eterno. Os grupos deveriam construir uma argumentação para defender o seu modelo. Para construção foi dada a liberdade de se buscar outras fontes para reforçar a argumentação, além do texto de apoio.

Um fator importante foi que se recomendou que os alunos não se preocupassem em defender o seu ponto de vista pessoal. Isso se fez por dois motivos: primeiro porque o resultado do pré-teste já indicou que a maioria dos alunos só conhecia o Big Bang; segundo, para que os alunos exercitassem a construção de argumentos além das suas convicções. Isso pode fazer com que eles tivessem contato com argumentos de teorias rejeitadas por eles, possibilitando uma reformulação de seus paradigmas individuais.

No dia marcado, cada grupo trouxe um cartaz divulgando a sua ideia. A turma foi dividida nos respectivos grupos. Inicialmente cada grupo fez uma explanação apresentando seus argumentos em defesa de sua teoria. Com isso, conseguiu-se dividir os argumentos dentro da polarização da turma em Big Bang e Universo Eterno.

Após as apresentações, foi desenvolvido um debate onde cada grupo, agora os três juntos defendendo o Big Bang e os outros três juntos defendendo o Universo Eterno, pudesse apresentar a sua argumentação de defesa do modelo defendido. Ao final do debate, fez-se uma grande roda de discussão, não mais dividida em grupos, onde cada aluno pode apresentar suas dúvidas construídas durante a confecção do trabalho.

Um fato salientado foi a dificuldade em se encontrar argumentos para o modelo do Universo Eterno quando comparado à diversidade de sítios de internet e livros sobre Big Bang. Isso mostra que, mesmo encontrando artigos com argumentos que mostrem que não é cientificamente hegemônica a proposta do Big Bang, a sua divulgação é maciça (NEVES, 2000).

Ao final foi solicitada uma avaliação rápida dos alunos onde se explicitasse o maior ganho com o trabalho. Um consenso foi o fator inovador. Para eles, a existência de duas teorias com possibilidade de serem aceitas como "verdade" para explicar algo do mundo natural, no caso a origem do universo, foi surpreendente. 


\section{Pós-teste}

Foi, então, preparado um novo questionário. A intenção era poder avaliar as ideias que persistiram nos alunos com perguntas relacionadas ao tema, mas que fossem diferentes do primeiro teste. Essa mudança provocou uma maior dificuldade na avaliação, porém ficou mais interessante para os alunos. Com perguntas diferentes, fica menos evidente a expectativa de uma resposta diferente da apresentada no pré-teste.

O questionário aplicado é apresentado a seguir, bem como os objetivos esperados em cada pergunta:

\section{Questionário do pós-teste}

1- Quando se produz uma campanha publicitária para um produto querendo lhe dar credibilidade, faz-se aparecer um cientista de jaleco afirmando as vantagens desse produto. Como você explica a utilização desse personagem.

Objetivo: Verificar junto aos alunos se a Ciência produz verdades absolutas. Usando como referencial Stephen Toulmin, que defende a coexistência de teorias e a sobrevivência da mais adaptada, esperasse verificar se após a discussão desenvolvida no trabalho, os alunos conseguem desenvolver essa percepção de que a verdade nas Ciências é efêmera e como a divulgação pode fazer com que uma teoria se adapte mais que outra.

2- "A Ciência produz verdades absolutas no tempo que sustentam a sociedade." Critique essa afirmação, concordando ou discordando com ela. Use argumentos para justificar sua resposta.

Objetivo: Igual à primeira, mas feita de forma mais direta.

3- Descreva como você acredita que surgiu a vida na terra.

4- Você acredita em geração espontânea? Justifique.

Objetivo: As questões 3 e 4 tem como objetivo verificar se os alunos conseguem enxergar um dilema. De forma indireta, essa divisão remete ao problema do Infinito x Finito, tal qual o modelo do Big Bang e do Universo Eterno. Quando se concebe que a vida surge na terra a partir de uma condição especial, fica uma ideia similar à do Big Bang. Quando se admite que a vida chega à Terra por outra via, e apenas se desenvolve aqui, não se questiona a sua origem ou começo, ficando uma opção semelhante ao Universo Eterno. O senso comum descarta a geração espontânea, mas ao mesmo tempo acredita que a vida na terra surgiu a partir de organização de proteínas. Isso seria uma geração espontânea aleatória.

O objetivo foi levantar um questionamento de um conflito entre interpretação de teorias bem como mais uma vez provocar uma reflexão sobre o Infinito x Finito.

5- Os fenômenos da natureza só têm uma explicação realmente correta. Critique essa afirmação, concordando ou discordando com ela. Use argumentos para justificar sua resposta. 
Objetivo: Essa pergunta evidencia a intenção de verificar se os alunos perceberam a natural dicotomia sobre verdade, absoluta ou efêmera, presente na Ciência. Entre os argumentos, espera-se encontrar as teorias sobre a origem do universo vista por eles.

\section{Análise dos resultados do Pós-teste}

Avaliando as respostas obtidas na primeira pergunta, foi possível perceber que, para este corpo discente, o cientista dá, por razões diversas, credibilidade ao produto. A maioria das respostas (34\%) apresentou o termo verdade absoluta como característica da ciência que se personifica no cientista. Seguindo, $27 \%$ responderam que a imagem do cientista garante a qualidade do produto, já que o mesmo tem uma formação contínua atingindo até mesmo a sabedoria. Uma resposta que descreve essa ideia é a do aluno 13C:

Aluno 13C: O personagem de um cientista de jaleco dá à população uma certa segurança. Desde o início das teorias Evolucionistas, naturalistas, etc., a Ciência adquiriu uma importância significativa e, o cientista, um status. Temos tendência a crer na Ciência como absoluta e no cientista ("o homem de jaleco branco") como o propagador dessa verdade absoluta.

Uma resposta que não representou um grande percentual (3\%) diz que existe uma visão da sociedade sobre a ciência como questão e fé. Apesar de ser um percentual pequeno, a associação se mostra muito pertinente ao trabalho, pois os alunos encontram uma visão dogmática dentro da ciência. A resposta abaixo representa essa visão:

Aluno 2 C: O marketing utiliza da fé que a sociedade tem na ciência. A ciência é quase uma religião. A pessoa tem mais facilidade em aceitar algo comprovado cientificamente mesmo que elas não consigam entender. Isso me lembra a Idade Média quando tudo que a Igreja falava era verdade. Talvez hoje o dogma seja o científico, ninguém quer parecer retrógrado contrariando a ciência.

A segunda pergunta teve uma maioria absoluta de respostas (92\%) que acredita na afirmação: A ciência produz verdades absolutas no tempo que sustentam a sociedade.

A resposta com maior incidência preconiza que essa verdade é efêmera. Mas apesar de efêmera, dá suporte à sociedade e pode mudar ao longo do tempo. Com 16\%, ficou uma ponderação que reitera a preocupação atual com a alfabetização científica. Os alunos disseram que a sociedade não tem formação para questionar a produção científica. E, ainda, com alguma representatividade nas respostas, $14 \%$ afirmam que têm na Ciência uma fé como se fosse religiosa. $\mathrm{O}$ aluno $21 \mathrm{C}$ colocou uma resposta que retrata bem esse padrão:

Aluno 21C: A afirmação não está correta, uma vez que não existem verdades absolutas. Acreditar que a Ciência está com toda a razão sobre a criação e o funcionamento do universo só pode ser interpretado como uma religião, palavra tão abominada pelos cientistas. É o mesmo que uma manifestação fundamentalista judaica ou cristã, por exemplo. 
Pelas respostas apresentadas na questão três, ficou evidenciado que, admitindo a correlação feita na concepção do pós-teste, existe uma tendência do grupo a buscar o finito. A grande maioria admitiu o surgimento da vida em um momento especial e exclusivo.

Mais da metade dos alunos (66\%) optou pela teoria de Oparin e Haldane que diz que a vida surgiu na terra a partir de moléculas inorgânicas que deram origem a moléculas mais complexas. O aluno $14 \mathrm{C}$ fez uma ressalva particular, que não apareceu em nenhuma das respostas, sobre a certeza da ausência de um poder divino.

Aluno 14A: Acredito na formação de moléculas orgânicas a partir de moléculas $i$ norgânicas, por conta de reações químicas, permitindo o aparecimento dos primeiros seres vivos, que sofreram inúmeras mutações até os seres vivos do mundo atual se estabelecerem. Não acredito em nenhuma intervenção divina.

A segunda maior incidência de respostas citou o Big Bang como fonte da vida ou de tudo que existe. Para essa parcela de alunos (16\%) parece que a vida surge junto com o universo e posteriormente ela se desenvolve na terra.

Com $9 \%$ das respostas, sendo a última parcela representativa, o aspecto religioso ressalta a mistura desse assunto com as crenças individuais dos alunos. As respostas apresentam uma dicotomia entre a crença na ciência e na sua religião. Assim, o fator necessário e especial para o surgimento da vida pode ser divino.

Para a questão quatro, a grande parte dos alunos (45\%) disse não acreditar na geração espontânea. Porém, ao se analisar as questões 3 e 4 respondidas por esse grupo, verificase que $69 \%$ deles descreveram o surgimento da vida como no modelo de Oparin e Haldane. Isso se mostra um resultado curioso. No momento que se admite condições "especiais" para "surgir" a vida em nosso planeta, a geração espontânea poderia ser um termo associado a esse momento.

Um quarto das respostas apenas afirmou que acredita em geração espontânea e 16\% dos alunos discriminaram que só pode ser concebida a geração espontânea no momento que se deu o surgimento da vida na terra, descrito por Oparin e Haldane. Após as condições iniciais, esse fenômeno não poderia se repetir.

A questão cinco teve uma distribuição de resposta da seguinte forma: $25 \%$ dos alunos concordam com essa afirmação e $69 \%$ deles discordam, ficando o restante indeciso, sem conseguir se posicionar. Essa pergunta foi marcada por uma diversidade muito grande nas justificativas apresentadas. $\mathrm{O}$ fato de mais da metade dos participantes discordar da afirmação pode ser atribuído ao trabalho desenvolvido sobre a origem do universo.

\section{Avaliação dos impactos do trabalho}

Um fato surpreendente aconteceu um mês após a aplicação do pós-teste. Foi publicado no jornal do colégio, "O Mamute", um texto intitulado "Perguntas sem resposta?". Ao ler o texto se reconhece que a discussão levantada nele se embasava na discussão feita junto 
às turmas pesquisadas. Então, os pesquisadores marcaram uma entrevista com as alunas que haviam escrito o texto, que aqui serão chamadas como aluna "Carla" e aluna "Elaine". Elas confirmaram que este texto era sim fruto do trabalho. Elas descreveram que o trabalho havia provocado nelas uma mudança muito grande na forma como enxergavam o mundo e a ciência. Além disso, avisaram que na edição seguinte do jornal já haveria um segundo texto, também baseado nas reflexões que o trabalho provocara nelas.

Foi pedido a elas, então, que relatassem de forma mais detalhada como o trabalho havia impactado e de que forma as levou a produzir aqueles textos. Elaine relatou que nunca havia pensado nessa questão do Finito e Infinito e Carla disse que já pensara na questão de forma diferente. Ela descreveu que sempre a incomodou a ideia de que haveria um número depois do outro, nunca chegando a um último número, revelando um desconforto com o infinito.

Quanto à Cosmologia, elas responderam que nenhuma das duas tinha noção do que se tratava. Elas relataram que talvez tivessem pensado em origem de tudo com uma visão religiosa. Carla ressaltou que lera um livro do cosmólogo Mario Novello, onde se aborda diversos assuntos de Física moderna e origem do universo. O nome do livro é Jogos da Natureza. A imagem de ciência delas era a trivial onde se imagina uma construção linear, contínua e sem competição.

Elas continuaram o relato dizendo ter sofrido uma grande mudança na forma de pensar sobre os temas discutidos. Elaine relatou ainda que com relação ao finito não mudou muita coisa. Carla concordou.

Carla descreveu que o texto provocou nela a curiosidade de saber mais sobre o assunto, dizendo: "Eu queria mais texto".

Elaine falou que o texto fez com que buscasse mais fontes sobre Cosmologia. Ela foi, então, a biblioteca do colégio e a bibliotecária ofereceu uma enciclopédia que não tinha nada sobre o Universo Eterno. Somente na internet ela encontrou uma "coisa incrivelmente pequena" (sic) falando da concepção antiga sobre Universo Eterno. Além disso, sempre após o Universo Eterno vinha algo relacionado ao Big Bang. Somente a proposta atual do Mario Novello tinha um pouco mais de material.

Elas relataram que a proposta do universo infinito se tornara mais confortável para elas, pois as leva a pensar no que existe fora do universo em expansão. Isso levantou uma discussão para as duas com relação ao desconforto do nada.

Por fim, descreveram que, após o trabalho, elas começaram também a questionar porque as explicações em ciência deveriam ser sempre matematizadas. Elas temem que a origem do universo possa ser explicada em termos totalmente desconhecidos por nós. Elas passaram a julgar que os seres humanos são muito pequenos diante do infinito e é uma pretensão muito grande achar que poderíamos propor uma teoria para essa origem. Por fim, Elaine citou 
o filme Horton 5 , que retrata "um mundo" dentro do pólen de uma flor, pertencente ao nosso mundo como o vemos. Carla terminou a entrevista dizendo que tomou repulsa a respeito do Big Bang e que ela havia lido durante o desenvolvimento do trabalho o livro "do Big Bang ao Universo Eterno", mas encontrou muito mais conforto na teoria do Universo Eterno.

\section{Conclusão}

O trabalho apresentado é resultado de uma discussão que se faz em torno de como introduzir temas de Natureza da Ciência em sala de aula. Apresentar duas teorias contemporâneas pode ajudar os alunos a perceberem a possibilidade de coexistência de hipóteses sobre o mesmo fenômeno e que evidências podem favorecer uma ou outra teoria. Assim, é possível perceber o diálogo presente na construção da ciência.

Baseado nesses resultados, na experiência vivida durante a aplicação do trabalho e nos depoimentos dos alunos participantes, ficou evidente a necessidade de introduzir discussões histórico-filosóficas nos cursos de Física. Alunos que tradicionalmente não se interessavam pela disciplina se mostraram participativos e engajados em responder o questionário.

A forma como a ciência é construída deve ser discutida em sala para quebrar, principalmente a visão de uma construção linear por acúmulo de conhecimentos, onde só exista um único paradigma vigente e que seja totalmente descontextualizada em relação à sociedade. Nessa concepção, a utilização de discussões em torno de Natureza da Ciência se mostra uma importante forma para tornar a visão do aluno mais adequada à realidade da construção da Ciência.

A construção de textos paradidáticos que se contraponham à visão dos livros didáticos utilizados nas escolas pode servir para a elaboração de uma nova concepção de ciência por parte dos alunos. O desenvolvimento de trabalhos com diferentes rotinas faz com que alunos assumam uma postura mais ativa dentro de sala.

\section{Bibliografia}

ALVES, R. Filosofia da Ciência: introdução ao jogo e a regras. São Paulo: Editora Loyola, 2000 .

BONDI, H; Gold, T. The Steady-State Theory of the Expanding Universe. Monthly Notices of the Royal Astronomical Society, v. 108, n. 252, 1948. Disponível em:

$<$ http://articles.adsabs.harvard.edu/cgi-bin/nphiarticle_query?bibcode=1948MNRAS.108..252 B\&db_key=AST\&page_ind=0\&plate_select=NO\&data_type=GIF\&type=SCREEN_GIF\&cla ssic $=$ YES $>$.

\footnotetext{
${ }^{5}$ Este filme é um desenho onde um elefante carrega uma flor e passa a interagir com uma sociedade que vive no pólen dessa flor. Título em português: Horton e o mundo dos quem.
} 
BRAGA, M. A Nova Paidéia: Ciência e Educação na construção da modernidade. Rio de Janeiro, Epapers, 2000.

BRAGA, M; GUERRA, A; REIS, J. C. O papel dos livros didáticos franceses do século XIX na construção de uma concepção dogmático-instrumental do ensino de física. Caderno Catarinense de Ensino de Física, v. 25, n. 3, p. 507-522, dez. 2008.

BRASIL, Ministério de Educação e Cultura. Secretaria de Educação Básica. Diretoria de Currículos e Educação Integral. Coordenação Geral do Ensino Médio. Programa Ensino Médio Inovador: Documento Orientador. 2013.

GUERRA, A.; REIS, J. C.; BRAGA, M. Um Julgamento no Ensino Médio - Uma estratégia para Trabalhar a Ciência sob Enfoque Histórico-filosófico. Física na Escola, Rio de Janeiro, v. 3, n.1, p. 8-11, 2002.

GUERRA, A.; BRAGA, M.; REIS, J. C. Um curso de Cosmologia na primeira série do Ensino Médio com enfoque histórico-filosófico. In: SIMPÓSIO NACIONAL DE ENSINO DE FÍSICA, XVIII, 2009, Vitória. São Paulo: SBF, 2009. v. 1

HÖTTECKE, D.; RIESS, F. Developing and implementing case studies for teaching science with the help of History and Philosophy. In: INTERNATIONAL HISTORY, PHILOSOPHY AND SCIENCE TEACHING CONFERENCE, X, 2009, South Bend. Disponível em: $<$ http://www3.nd.edu/ ihpst09/papers/Hoettecke_Paper_IHPST09.pdf>.

LIMA, S. C. de; TAKAHASHI, E. K. Sobre as competências envolvidas no processo de promover a aprendizagem significativa. IN: ENCONTRO NACIONAL DE PESQUISA EM ENSINO DE FÍSICA, XI, 2008, Curitiba.

MATTHEWS, M. R. História, Filosofia e Ensino de Ciências: a tendência atual de reaproximação. Caderno Catarinense de Ensino de Física, Florianópolis, v. 12, n. 3, p. 164-214, dez.1995.

MCCOMAS, W. F. Seeking historical examples to illustrate key aspects of the nature of science. Science \& Education, v. 17, p. 249-263, 2008.

MOREIRA, M. A. Pesquisa básica em educação em Ciências: uma visão pessoal. Revista Chilena de Educación Científica, v. 3, n. 1, p. 10-17, 2004.

NEVES, M. C. D. A questão controversa da cosmologia moderna: Hubble e o infinito parte1. Caderno Brasileiro de Ensino de Física, v. 17, n. 2 p. 189-204, ago. 2000.

NOVELlO, M. O que é cosmologia? A revolução do pensamento cosmológico. Rio de Janeiro: Editora Jorge Zahar, 2006. 
NOVELlO, M. Do Big Bang ao Universo Eterno. Rio de Janeiro: Editora Jorge Zahar, 2010.

PEDUZZI, L. O. Q.; KÖHNLEIN, J. Uma discussão sobre a Natureza da Ciência no ensino médio: um exemplo com a teoria da relatividade restrita. Caderno Brasileiro de Ensino de Física, v. 22, n. 1, p. 36-70, abr. 2005.

PINO, P. V.; OSTERMANN, F.; MOREIRA, M. A. Concepções epistemológicas veiculadas pelos PCNs na área de Ciências naturais de $5^{\circ}$ a $8^{\circ}$ série do ensino fundamental. In: ENCONTRO NACIONAL DE ENSINO DE FÍSICA, IX, 2003, Curitiba.

SINGH, S. Big Bang. Rio de Janeiro: Editora Record, 2006.

TOULMIN, S. The Philosophy of Science: an introdution. Londres: Ed. Willian Brendon and son, 1953. 